\title{
NUEVOS HORIZONTES DE ECONOMÍA ÉTICA EN TIEMPO DE NEUROCIENCIA*
}

\author{
JESÚS CONILL SANCHO \\ Universidad de Valencia
}

\begin{abstract}
RESUMEN. En el tema de los «Nuevos horizontes de economía ética en tiempo de neurociencia» se entremezclan lo que hoy se suele entender como ciencias naturales, ciencias sociales y humanidades (o ciencias humanas y ciencias del espíritu [Geisteswissenschaften], y todas ellas bajo el nuevo imperativo tecnológico (que impele incluso a considerar la ciencia en general como tecnociencia). Situados ya en este contexto de nuestro tiempo, sentimos de modo especial el predominio de lo económico, que se ha encarnado en los procesos de globalización y mundialización. Pero asimismo en nuestro horizonte histórico no es fácil sentir que vayan unidas la economía y la ética. Lo más normal es que se susciten recelos y sospechas, tanto por parte de los profesionales como de los ciudadanos.
\end{abstract}

PALABRAS CLAVE: economía, ética, neurociencia, economía ética, tecnociencia, ciencia, ciencias humanas.

\section{New Horizons of Ethics and Economy in Neuroscience Time}

ABSTRACT. The theme of «New horizons of ethical economics in neuroscience time» is intermingled with what is now commonly understood as natural sciences, social sciences and humanities (or human sciences, and the sciences of the spirit [Geisteswissenschaften]), all of them under the new technological imperative (impelling even to consider science in general as technoscience). In this context of our time, we feel in a special way the predominance of economics, which has become incarnated in the processes of globalization. Our historical horizon is not easy to feel that the economy and ethics are linked together. The most common thing is to raise suspicions, both by professionals and citizens.

KEY WORDS: economics, ethics, neuroscience, ethical economics, technoscience, science, human sciences.

\section{INTRODUCCIÓN}

En el tema de los «Nuevos horizontes de economía ética en tiempo de neurociencia» se entremezclan lo que hoy se suele entender como ciencias naturales, ciencias sociales y humanidades (o ciencias humanas y ciencias del espíritu [Geisteswissenschaften], y todas ellas bajo el nuevo imperativo tecnológico (que impele incluso a considerar la ciencia en general como tecnociencia).

Situados ya en este contexto de nuestro tiempo, sentimos de modo especial el predominio de lo económico, que se ha encarnado en los procesos de

* Este estudio se inserta en el Proyecto de Investigación Científica y Desarrollo Tecnológico FFI2013-47136-C2-1-P, financiado por el Ministerio de Economía y Competitividad, y en las actividades del grupo de investigación de excelencia PROMETEO de la Generalidad Valenciana. Y tiene su origen en la Lección Magistral pronunciada en la Universidad Interamericana de Puerto Rico, en septiembre de 2014. 
globalización y mundialización. Pero asimismo en nuestro horizonte histórico no es fácil sentir que vayan unidas la economía y la ética. Lo más normal es que se susciten recelos y sospechas, tanto por parte de los profesionales como de los ciudadanos. A lo sumo, se piensa que la ética ejerce una función cosmética en la vida económica, con el fin de crear una buena imagen o reputación. Frente a esta sensación inmediata, convertida ya en un prejuicio bastante extendido, de que el mundo económico y el ético son irremediablemente incompatibles, en primer lugar, quisiera recordar algunos hitos históricos que pueden iluminar nuestra mente y ofrecernos pistas para comprendernos a nosotros mismos, es decir, cómo es que hemos llegado a creer lo que creemos actualmente sobre la relación entre ética y economía. Porque esta creencia es un producto histórico, una interpretación, que está marcando nuestra vida real.

\section{Horizontes Clásicos, ANTIGUO Y MODERNO, DE ECONOMÍA ÉTICA}

Ahora bien, lo primero que debemos recordar es que la primera relación entre economía y ética no fue la que ahora nosotros generalmente sentimos y vivimos, porque el primer horizonte de la economía era de carácter intrínsecamente ético (ético-político). Se suele aludir al doble origen de la Economía como disciplina en el siglo IV antes der Cristo, tanto en la Filosofía práctica aristotélica (en el libro I de la Política, el «peri oikonomías») como en el Arthasastra ${ }^{1}$ de Kautilia ${ }^{2}$.

En la filosofía aristotélica, la economía era primordialmente el arte de administrar la casa (el oikós) y formaba parte de la filosofía práctica, junto con la ética, la política e incluso la retórica. En esta concepción la economía es una de las actividades humanas, a saber, la que se ocupa de administrar los bienes para satisfacer las necesidades. Por tanto, hay orden racional, natural (phýsis) y comunitario (koinonía), el bien de la comunidad doméstica (oikológico) y, por extensión, de la ciudad (ético-político). De la economía (que trata de la utilización —administración- de los bienes) hay que distinguir la crematística, que es el arte productivo o de adquisición de riqueza y recursos. No obstante, hay dos tipos de arte adquisitivo o crematística: 1) el que procura los recursos necesarios para la vida (la riqueza que basta para vivir bien, pero que no es ilimitada); y 2) el que no parece tener límite. Esta segunda clase de crematística va contra el orden racional natural, porque no tiene límite. De ahí el rechazo tradicional de la usura.

Así pues, en el horizonte clásico antiguo, en la versión aristotélica, la economía forma parte de la filosofía práctica en conexión intrínseca con la ética y la política, tiene un carácter comunitario y un enfoque holista, en el que

1 Consistiría en «instrucciones sobre la prosperidad material» y en una cierta «ciencia de la riqueza».

2 Fue consejero y ministro del emperador de India Chandragupta (siglo IV a.C.). 
el todo es anterior a las partes, por tanto, se puede hablar realmente de un bien común, de un interés común, que mantiene unidas a las partes; y está al servicio de la satisfacción de las necesidades, que son "por naturaleza» limitadas. He aquí una de las cruciales diferencias con el enfoque moderno de la economía, en el que no se puede afirmar del mismo modo que las necesidades son "por naturaleza» limitadas, porque en la modernidad se tiende a confundirlas con los deseos, que sí pueden ser ilimitados (a diferencia de las necesidades vitales, que son limitadas). Como tampoco se podrá mantener el sentido holista y comunitario. Aunque se seguirá manteniendo la vinculación de la economía con la ética y la política dentro de una nueva filosofía práctica.

En efecto, también en el horizonte moderno clásico se sigue manteniendo una vinculación entre el sentido moral y el técnico de la economía, como muestra el caso paradigmático de Adam Smith $(1723-1790)^{3}$, profesor de Filosofía Moral en la Universidad de Glasgow (Escocia) [a partir de 1752], que en 1759 publico su libro Teoría de los sentimientos morales (en el que su teoría ética está basada en la «simpatía» entre los seres humanos) y en 1776, un libro considerado fundacional de la economía moderna, titulado Investigación sobre la naturaleza y causas de la riqueza de las naciones. Así pues, el surgimiento de la economía moderna clásica está ligado también a la filosofía moral y se entenderá como «Economía Política». Lo que ocurre es que el contexto histórico de la economía y el sentido de la ética habían cambiado.

Emerge con fuerza la economía mercantil, basada en el intercambio, debido al incremento del comercio. El «dulce comercio», porque es mejor comerciar que guerrear. También aquí, en economía, se aplicaría la apreciación kantiana sobre la política y el derecho, mostrando que preferir el comercio a la guerra lo entendería "hasta un pueblo de demonios, con tal de que tuvieran inteligencia». Al parecer, visto el panorama internacional, ni ese mínimo hemos aprendido bien.

Emerge un sistema de organización económica, en el que ésta no está separada de la sociedad, sino más bien la configura como [sociedad] comercial y mercantil. De tal manera que la actividad económica está entremezclada con los elementos morales de la sociedad, cuyo nuevo punto de partida no es el todo, sino el individuo como sujeto (moral, social y económico, interesado por lo suyo) y su primer modo moderno de entender la libertad. En este nuevo contexto moderno, las relaciones entre los individuos se establecen principalmente mediante la figura del contrato, igual que en la política (como queda patente en las diversas teorías del contrato como legitimación de la vida política), también en la economía. El intercambio en la sociedad comercial se configura mediante contratos en los que lo que se busca son las ventajas mutuas. Por tanto, el orden social y el económico no se pueden separar, porque

3 Y han destacado también las relevantes interpretaciones del surgimiento de la economía moderna de Max Weber [La ética protestante y el espíritu del capitalismo], Werner Sombart [El burgués], Tawney, Robertson, Chafuen, etc. 
de lo que en último término se trata es de la realización de los individuos en libertad dentro de un marco político y social, de ahí que la economía moderna clásica se comprenda como «Economía política», basada en una ética moderna que parte del individuo ejerciendo su libertad.

Por eso, cuando se cita el famoso pasaje de Adam Smith «no es la benevolencia del carnicero, del cervecero o del panadero la que nos procura el alimento, sino la consideración de su interés propio ${ }^{4}$. No invocamos sus sentimientos humanitarios (...); ni les hablamos de nuestras necesidades, sino de sus ventajas $»^{5}$, hay que contextualizarlo y completar esta perspectiva con otras que también aparecen en la misma obra. En el intercambio lo decisivo no son las necesidades, sino las ventajas mutuas.

Smith describe de modo personificado el mecanismo del intercambio (dentro de un capítulo titulado «Del principio que motiva la división de trabajo») como expresión de una «propensión a permutar, cambiar y negociar una cosa por otra», una propensión de la que se pregunta si no es probablemente «la consecuencia de las facultades discursivas y del lenguaje»". Pues, "en una sociedad civilizada [el hombre] necesita a cada instante la cooperación y la asistencia (...). El hombre reclama en la mayor parte de las circunstancias la ayuda de sus semejantes y en vano puede esperarla sólo de su benevolencia. La conseguirá con mayor seguridad interesando en su favor (...) [a los otros] y haciéndoles ver que es ventajoso para ellos hacer lo que les pide. Quien propone a otro un trato le está haciendo una de esas proposiciones. Dame lo que necesito y tendrás lo que deseas, es el sentido de cualquier clase de oferta, y así obtenemos de los demás la mayor parte de los servicios que necesitamos» ${ }^{7}$.

«Sin la inclinación al cambio, a la permuta y a la venta cada uno de los seres humanos hubiera tenido que procurarse por su cuenta las cosas necesarias y convenientes para la vida ${ }^{8}$. Los intercambios se basan en tratos interesados.

Pero en este marco económico de intercambio, aunque «nadie se propone, por lo general, promover el interés público, ni sabe hasta qué punto lo promueve», cuando se busca la seguridad y la ganancia propia, "es conducido por una mano invisible a promover un fin que no entraba en sus intenciones. Mas no implica mal alguno para la sociedad que tal fin no entre a formar parte de sus propósitos, pues al perseguir su propio interés, promueve el de la sociedad de una manera más efectiva que si esto entrara en sus designios. No son muchas las cosas buenas que vemos ejecutadas por aquellos que presumen de servir sólo el interés público»?

4 Hay que distinguir «self-love» (amor propio) de «selfishness» (egoísmo, incompatible con la simpatía).

5 A. Sмiтн, La riqueza de las naciones, F.C.E., México, 1958, (reimpr. 1982), p. 17.

6 Ibid., p. 16. En el orden del intercambio, la motivación es una cierta cooperación.

7 Ibid., pp. 16-17.

8 Ibid., p. 18.

9 Ibid., p. 402. De aquí surgen dos asuntos: 1) las consecuencias no intencionadas y 2) la armonía de fondo (¿conflicto irresoluble?). 
Un error demasiado habitual ha sido confundir la posición de Smith con la de Mandeville. Porque no hay que confundir el interés propio y «la tendencia al intercambio» con un vicio. El propio Smith lo clara en la parte VII de La teoría de los sentimientos morales ${ }^{10}$ sobre «los sistemas licenciosos». Para Smith, el sistema de Mandeville elimina la distinción entre el vicio y la virtud, por lo que esta tendencia es «totalmente perniciosa»; «la gran falacia del libro del Dr. Mandeville [La fábula de las abejas] estriba en que representa cualquier pasión como plenamente viciosa (...) y por medio de esta sofistería establece su conclusión favorita: los vicios privados son beneficios públicos» ${ }^{11}$. Adam Smith rechaza la posición de Mandeville, porque considera que es una nefasta interpretación de la motivación humana, ya que no permite distinguir entre diversos tipos de pasión (la justa y razonable por lo más noble, la injusta, absurda y ridículo por lo más bajo, y la frívola como la vanidad) ${ }^{12}$.

Por otra parte, hay que completar la visión de Smith sobre el valor del mecanismo del mercado con la necesidad de someter a un estudio crítico el papel de los mercados ${ }^{13}$. Hay una severa advertencia de Smith sobre los «pródigos y aventureros» en el uso del dinero, porque provocan y fomentan el despilfarro social. Su argumento, tal como lo interpreta Sen es que las señales del mercado pueden ser engañosas y las consecuencias del libre mercado pueden significar un gran despilfarro de capital. A Smith le preocupó el problema del despilfarro social y la pérdida de capital productivo, y que la búsqueda de ganancias privadas, impulsada por motivaciones cortas de miras, provocara pérdidas sociales. Apunta, pues, a que en algunas circunstancias la búsqueda del beneficio privado vaya en contra de los intereses sociales. Y esta preocupación sigue siendo relevante hoy en día: nos advierte de los límites del mecanismo del mercado y de la necesidad de mantener una actitud crítica de discernimiento. Se necesitan instancias de control para que sea realizable el sistema de la libertad" de la «sociedad comercial».

\section{TRANSFORMACIÓN CONTEMPORÁNEA DE LA ECONOMÍA: PROCESO DE SEPARACIÓN (AUTONOMIZACIÓN) DE LA ECONOMÍA MODERNA}

A pesar de que en sus orígenes antiguos y modernos la economía está ligada a la ética socio-política, y aunque en el surgimiento de la economía moderna la ética juega un papel decisivo, el proceso moderno de racionalización, desmitificación y «desencantamiento» ha afectado también al modo de concebir y practicar la actividad económica. A medida que avanzó el proceso efectivo de racionalización moderna, fue predominando el lado positivista y técnico de

\footnotetext{
10 La teoría de los sentimientos morales Alianza, Madrid, 1997, pp. 534 ss.

11 Ibid., p. 543.

12 Ibid., 538 s.

13 Vid. A. Sen, Desarrollo y libertad, Planeta, Barcelona, 2000, pp. 156 ss.
} 
la economía, perdiéndose de vista el sentido ético, hasta el punto de que se ha generalizado la convicción de que la racionalidad económica, convertida para muchos en el modelo de la racionalidad modera (junto con la tecnológica), excluye todo enfoque ético. De tal manera que se ha establecido una escisión ente lo ético y lo técnico-científico en la economía, que constituye un problema social, al que todavía no hemos sabido dar una solución, ni en la teoría ni en la práctica.

Hoy en día, la creencia todavía predominante es la de la separación tajante entre economía y ética. Pero de lo que se trata es justamente de saber si la modernidad implica necesariamente una separación semejante, o si una reflexión en profundidad no nos ofrecería alguna otra posible salida. Conviene, pues, saber por qué se ha producido esta situación.

Ha habido un proceso de separación en el que han influido diversas líneas de fuerza, cuya convergencia ha producido el mismo efecto de desvinculación de la economía respecto de la ética. Podemos destacar principalmente tres factores: axiológico, epistemológico y profesional-institucional.

En primer lugar, la liberación de la economía respecto de la tutela de la moral (y de la religión) en el contexto de las sociedades tradicionales. La modernización (capitalista o socialista) produce una autonomización de la esfera económica. Tal vez haya sido éste el motor más potente - junto con la innovación tecnológica- para ir sustituyendo el universo simbólico tradicional por otra forma de entender el mundo y de organizarlo.

Una de las consecuencias ha sido el cambio axiológico. Por ejemplo, se empezó a percibir como «natural» y moralmente justificado el «afán de lucro». Es más, progresivamente se iba convirtiendo en algo beneficioso y ventajoso para la interrelación humana y para el funcionamiento, no sólo de la economía sino dela sociedad. Incluso fue cambiando el modelo de ser humano en el imaginario colectivo: las personas se entienden como individuos, egoístas racionales, calculadores de ventajas y beneficios, y al parecer insensibles a los argumentos morales.

Este proceso de racionalización (desmitificación y desencantamiento) se ha interpretado por lo general como desaxiologización bajo el predominio del positivismo tecnocrático, que defiende la «neutralidad axiológica» (Wertfreiheit) y favorece la pérdida de sentido ético en las actividades económicas. Sin embargo, también cabe interpretar este proceso como una transvaloración, no precisamente al estilo de la «Umwertung» nietzscheana, sino de muy otro tipo, porque emergen unos nuevos valores, que rigen la vida real y crean la cultura económica moderna ${ }^{14}$. La que vence es la transvaloración economicista (más la tecnológica).

En segundo lugar, junto al cambio axiológico en la mentalidad social, se produce un cambio epistemológico en la concepción de la ciencia. El modelo

14 No reconocer esta carga axiológica convierte esa actitud en una ideología (deformadora). Vid. J. Habermas, Ciencia y técnica como ideología y Conocimiento e interés; también K.O. Apel (La transformación de la filosofía) y M. Scheler (Sociología del saber). 
de interpretación de la actividad económica tiende a ser mecanicista (por influencia de la ciencia reina en la modernidad, que es la Física matematizada): los agentes económicos, que buscan su beneficio, se consideran «fuerzas» dentro de un acontecer entendido como un proceso natural, un "campo» de fuerzas, del que es posible establecer «leyes» del movimiento económico.

Con lo cual la economía deja de pertenecer a la filosofía práctica, deja de ser una ciencia social e histórica, para someterse primordialmente a un proceso de formalización y matematización dentro del enfoque mecanicista reinante e imperante en la ciencia moderna. Por consiguiente, a los mecanismos económicos así entendidos ya no es posible aplicarles las categorías éticas, como la justicia social. Un ejemplo paradigmático es la inteligente posición al respecto de Hayek, según la cual no se necesita la ética en el acontecer natural de la economía moderna ${ }^{15}$. El sistema económico se concibe como un mecanismo funcional, en el que el presunto «homo oeconomicus» funciona como una máquina reactiva a los estímulos del campo económico (de inputs y outputs). Triunfo de la máquina algorítmica en el campo de fuerzas.

En tercer lugar, este cambio axiológico y epistemológico se traduce en la vida práctica y se transfiere en la vida social mediante la formación de los profesionales, el diseño de las organizaciones y la configuración de las instituciones.

Ahora bien, el proceso moderno de separación y autonomización respecto de la ética se ha revertido y convertido en una primacía de lo económico en la vida y sobre la ética. La creciente tendencia a la economización de todos los ámbitos de la vida ha instaurado la figura del «homo oeconomicus» (que mejor sería decir «homo crematisticus»): el ser humano como agente económico interpreta la realidad bajo la perspectiva de «coste-beneficio». Parte del hecho de que los recursos son escasos y tiende a satisfacer sus preferencias intentando maximizar el beneficio mediante las estrategias más eficaces (eficientes). Y este es el enfoque que se ha ido generalizando en la vida pública y privada. Por esta vía se ha producido un creciente proceso de absorción de fenómenos que no eran estrictamente económicos (no de mercado) por parte de la racionalidad económica, por la perspectiva analítica económica, aplicable a cualquier campo del comportamiento humano. Pues toda acción y omisión (en el campo que sea) puede considerarse desde la perspectiva de los costes de oportunidad, del análisis coste-beneficio. La economía proporciona una teoría general de la racionalidad y del análisis de comportamiento humano, en definitiva, un marco de inteligibilidad para explicar (presuntamente) todos los factores del comportamiento humano. Se trata de lo que se ha denominado «imperialismo económico», que ha intentado ofrecer incluso una teoría económica de la

15 F. HAYEK, «El espejismo de la justicia social» (Derecho, legislación y libertad, vol. II) y La fatal arrogancia. Los términos «justicia social» o «económica» carecen de contenido y de fundamento. Se trata de una "superstición», que sólo sirve para apoyar los intentos de satisfacer apetencias propias de los ancestrales grupos tribales, que no pueden jugar ningún papel en una sociedad como la actual, libre y compleja. 
moral ${ }^{16}$, con lo cual, más que de un horizonte ético de la economía habría que hablar de un horizonte económico de la ética (asimismo de la política, la cultura, la formación y la vida personal). Porque se piensa que no hay una ética englobante (predominante), capaz de fundamentar racionalmente normas morales universalmente vinculantes, poniendo en cuestión las pretensiones del cognitivismo ético (de Kant, Rawls, Apel y Habermas).

\section{Nuevos horizontes de ECONOMÍA ÉTICA}

\section{Crisis y transformación de la economía}

Desde hace ya tiempo asistimos a una revisión crítica de la teoría económica desde diversos frentes y a nuevas propuestas, más allá de la economía convencional. Hay un reconocimiento de la actual crisis de la economía ${ }^{17}$, cada vez se oyen más voces críticas.

Hay quienes insisten en que la Economía no es una ciencia física, sino una ciencia social e histórica, es decir, una ciencia humana. Algunos incluso ponen el dedo en la llaga al decir que no es una ciencia predictiva, sino reconstructiva e indicativa. De ahí que sea necesario reflexionar sobre los presupuestos sobre los que opera en cada una de sus formulaciones. Por ejemplo, se critica especialmente el presupuesto del «comportamiento racional», que ha servido presuntamente para predecir el comportamiento ${ }^{18}$.

Hay propuestas de todo tipo. Desde las que plantean de nuevo un cambio de sistema económico, aunque hoy en día son las menos, una vez que incluso los socialistas democráticos (al menos) han abandonado la idea de cambiar de sistema económico. Hasta aquéllos que propugnan un cambio de paradigma o de enfoque en la Economía, dado que consideran que la economía convencional ha fracasado (porque, a pesar de seguir manteniendo una posición de poder, sin embargo, no sirven para resolver los problemas que el mundo tiene planteados); o bien que se ha empobrecido, al perder su sentido de «Economía política» y, especialmente, por haberse separado de la ética.

De ahí que hayan surgido una serie de iniciativas que han intentado incorporar explícitamente la ética mediante una vinculación sistemática de economía y ética. Por ejemplo, el liberalismo social (a partir de Rawls), la

16 K. Homann, Anreize und Moral, LIT, Münster, 2003; vid. la teoría de sistema de N. Luhmann (Soziale Systeme, Frankfurt, Suhrkamp, 1984). Por su parte, Homann, en vez de una fundamentación de la moral a partir de un concepto fuerte de «razón», intenta fundamentar la vinculación moral a partir de los «intereses» y las motivaciones. Y, según Luhmann, la ética es irrelevante para los procesos comunicativos que se establecen en los sistemas funcionales.

17 Vid., por ejemplo, A. Hirschmann, P. Ormerod, L. Thurow, D. Schweickart, L. de Sebastián, R. Velasco, etc.

18 Id. A. SEN, Sobre ética y economía, Alianza, Madrid, 1989, p. 29. 
ética de la economía constitucional (J. Buchanan), el nuevo institucionalismo económico (North), la socioeconomía comunitarista (Etzioni), el republicanismo económico (Sandel, Ackerman, Pettit), el «capital social» (Putnam), la teoría económica de la moral (Homann), la ética económica y empresarial basada en la praxis dialógica (Steinmann), la ética económica comunicativa (integrativa) de Ulrich. Más recientemente, la psico-economía de Kahneman y Tversky, así como la nueva teoría de los comunes de Ostrom.

Y, de un modo todavía más significativo, hay que resaltar en el nuevo horizonte contemporáneo la aportación a una auténtica «economía ética» del «enfoque de las capacidades» de Amartya Sen (al que han contribuido también desde sus respectivas posiciones filosóficas Martha Nussbaum y Adela Cortina). Se trata de un nuevo enfoque económico que tiene un trasfondo ético más allá del utilitarismo (en cualquiera de sus formas), dando un paso decisivo, ya que ha sido la ética utilitarista la que ha acompañado a la teoría económica en los últimos tiempos (explícita o implícitamente).

El pensamiento económico de Sen constituye un síntoma de que puede que se esté abriendo realmente un nuevo horizonte de economía ética. Pues Sen mantiene explícitamente que «la naturaleza de la economía moderna se ha visto empobrecida sustancialmente por el distanciamiento que existe entre la economía y la ética» ${ }^{19}$.

Otro buen ejemplo (que cabe relacionar asimismo con la influencia de Sen) son los «Informes sobre el desarrollo humano» del PNUD (Programa de las Naciones Unidas para el Desarrollo), en los que tanto el enfoque fundamental como los indicadores de la pobreza son cualitativamente diferentes a los de la economía convencional. Por ejemplo, los nuevos indicadores del desarrollo humano se enfocan en función de las luchas por las libertades humanas ${ }^{20}$.

La cuestión básica del nuevo enfoque de Sen consiste en hacernos conscientes de que cuando preguntamos por la riqueza y por la prosperidad (y por la pobreza), no basta con preguntarse por el dinero, o por el PIB per cápita, sino también por otros determinantes, por otros factores vitales y, por tanto, necesitamos contar con otras fuentes de información, por ejemplo, sobre la calidad de vida y sobre qué capacidad tienen las personas para conducir su propia vida, es decir, cuál su libertad real21. Por tanto, hay que tener información sobre la seguridad, las expectativas de vida, la salud, los servicios médicos, la educación, el trabajo, las libertades, las relaciones familiares, la situación de las mujeres, etc. Porque "la vida es más que un conjunto de relaciones comerciales» y «el ser humano (...) es un "misterio insondable", que no puede expresarse completamente en una "forma tabular" ${ }^{22}$.

19 A. SEN, Sobre ética y economía, p. 25.

20 Vid., por ejemplo, el Informe sobre Desarrollo Humano 2000, cap. 2; asimismo Denis Goulet (Development Ethics at Work, Routledge, London and New York, 2006) y Emilio Martínez Navarro (Ética para el desarrollo de los pueblos, Trotta, Madrid, 2000).

21 Que sólo es posible en cierto marco de justicia.

22 M.C. Nussbaum y A. Sen (coord.), La calidad de vida, F.C.E., México, 1996, p. 16. 
Se requiere información sobre «lo que las personas pueden hacer y ser». Sin duda es más complejo medir y evaluar estas dimensiones, pero es necesario si se quiere "saber cómo le va a la gente» su vida en las diversas partes del mundo. De ahí la necesidad de contar con nuevos indicadores con los que se pueda medir la calidad de vida. Porque ya no es suficiente ni conveniente seguir con un enfoque utilitarista, sino que hay que buscar innovadoramente otro instrumental para atender a las diversas actividades que hacen floreciente la vida humana ${ }^{23}$. Este es uno de los propósitos del «enfoque de las capacidades» de Sen: «encontrar criterios adecuados para valorar la calidad de vida ${ }^{24}$.

Ahora bien, la base más significativa de este enfoque de las capacidades (aun cuando está dentro de las tradiciones más relevantes de la economía y la ética) ${ }^{25}$ está constituida por «la perspectiva de la libertad», con la que se reintroduce en la teoría económica un ineludible trasfondo ético: de ahí que quepa denominarla «economía ética», cuyos ingredientes son la libertad y la calidad de vida ${ }^{26}$, la libertad y la justicia, sin la que no es posible la libertad real.

\section{Posible ampliación neuroeconómica de la economía ética}

También a la Economía le está afectando la revolución de las neurociencias, de manera que ya se han desarrollado importantes investigaciones en «neuroeconomía» y «neuromarketing» (de un modo semejante a como ha ocurrido en otras disciplinas, por influencia de las innovaciones biotecnológicas en neurología, que permiten detectar y visualizar [image] la actividad cerebral, no sólo mediante los electroencefalogramas, sino con las nuevas técnicas del $\mathrm{PET}^{27}$ y de la $\left.\mathrm{fMRI}^{28}\right)^{29}$.

A pesar de ciertas reticencias iniciales, la creciente innovación neurológica de los últimos decenios ya está dando sus frutos, al posibilitar el estudio objetivo de los fenómenos subjetivos, en concreto, la actividad cerebral en la toma de decisiones, es decir, los procesos neurobiológicos que subyacen a la toma

23 No basta el utilitarismo que hay detrás de la teoría de las preferencias reveladas, ni tampoco sus axiomas y algoritmos.

24 M. C. Nussbaum y A. Sen (coord.), La calidad de vida, F.C.E., p. 17.

25 Dentro de la economía, la Economía clásica, la Economía del bienestar y la del desarrollo; y dentro de la filosofía moral, Aristóteles, Adam Smith, Marx, Rawls y, a mi juicio, también Kant.

${ }_{26}$ No hay que confundir wellfare y well-being, es decir, bienestar y bien-ser; éste último es el que se aleja de la concepción utilitarista del bienestar y se relaciona con la condición dela persona (haciendo referencia a otros aspectos como las capacidades, las oportunidades, las ventajas, de ahí que se use el término «calidad de vida»).

27 Escáner de tomografía por emisión de positrones, que mide el flujo sanguíneo en el cerebro

${ }_{28}$ Resonancia magnética funcional, que rastrea el flujo sanguíneo en el cerebro basándose en la oxigenación de la sangre (la «señal bold»).

29 Vid. Adela Cortina, Neuroética y neuropolítica, Tecnos, Madrid, 2011; A. Cortina (ed.), Guía Comares de Neurofilosofía práctica, Comares, Granada, 2012. 
de decisiones ${ }^{30}$. Una de las consecuencias de estos estudios es que también contribuyen a revisar la concepción estándar de la racionalidad económica, que está centrada en la maximización de la utilidad. El estudio de las condiciones neurobiológicas de la elección está conduciendo a variar los procesos algorítmicos que intentaban explicar la toma de decisiones. De manera que el enfoque neuroeconómico podría servir de alternativa al imperio de las teorías normativas y axiomatizadas de la economía contemporánea. Por de pronto, estos nuevos estudios neurológicos hacen juego con la «teoría prospectiva (prospect)» de Kahneman y Tversky ${ }^{31}$, que es una forma no-normativa de la teoría de la utilidad esperada (expected). Y además contribuyen a acercar la teoría económica de los denominados «econos» (agentes racionales) al mundo real de los agentes «humanos».

Son muchas ya las aportaciones del enfoque neuroeconómico al estudio de la incertidumbre, la evaluación de los riesgos, la aversión a la ambigüedad y a la pérdida, los sesgos, la relevancia de los sentimientos, las emociones y los valores en las decisiones, etc. Pues la investigación de las bases cerebrales del presunto agente racional (los procesos neurobiológicos que subyacen a la toma de decisiones) ofrece una nueva vía para superar la homogeneidad motivacional (que, por ejemplo, ya Sen superaba con su enfoque de las capacidades en relación con la motivación moral).

Esta ampliación de las motivaciones se ha aplicado de manera espectacular en la actividad inversora. Estudiando la actividad cerebral en las inversiones financieras algunas investigaciones han mostrado que nuestros cerebros inversores a menudo nos conducen a hacer cosas que no tienen sentido lógico, sino emocional. No es que seamos irracionales, sino que el cálculo se combina con reacciones a riesgos, recompensas, recuerdos y presentimientos, que nos hacen sentir esperanza, avidez, sorpresa, miedo ${ }^{32}$, pánico, pesar, felicidad, etc.

En consecuencia, a través de todos estos nuevos estudios se logra un nuevo impulso para revisar la racionalidad económica estandarizada, estableciendo sus límites y su necesaria flexibilización, incluso plantearse si no habría que hablar de una «neurorracionalidad» de la elección, con importantes consecuencias para algunos aspectos éticos, como los siguientes: 1) no somos decisores racionales óptimos que maximizan utilidad; 2) necesitamos establecer relaciones de confianza, que pueden ser favorecidas por algunos neurotransmisores, como la oxitocina; 3) existen bases neurológicas para la cooperación e incluso para el sentido de la justicia en la actividad económica.

30 Ch. Suhler y P. Churchland, "The neurobiological basis of morality», en The Oxford Handbook of Neuroethics, edited by J. Illes y B.J. Sahakian, Oxford University Press, 2011, pp. 33-58 (especialmente, p. 34); Paul W. Glimcher, Colin F. Camerer, Ernst Fehr, and Russell A. Poldrack (eds.), Neuroeconomics: Decision Making and the Brain, Elsevier, 2009.

31 «Teoría de las perspectivas», según la traducción en Daniel Kahneman, Pensar rápido, pensar despacio, Debate, Barcelona, 2012.

32 Jason Zweig, Your Money and your Brain, New York, London, Toronto, Simon and Schuster Paperbacks, 2007. 
Algunos experimentos neurobiológicos han ofrecido datos que muestran la conexión entre el córtex prefrontal medial y algunas estrategias cooperativas que se desvían de la predicción normativa estándar, lo cual ha hecho pensar en la hipótesis de si el modelo no-normativo de la cooperación no tendrá su base en los circuitos del córtex prefrontal.

Asimismo, el estudio neurocientífico de la recompensa en las decisiones ofrece datos (aunque falta una teoría coherente para su interpretación de conjunto) que ponen en entredicho la interpretación de los individuos como decisores óptimos que maximizan utilidad. Un aspecto muy relevante es el papel de los neurotransmisores en el proceso de la recompensa, por ejemplo, la dopamina. Es éste un asunto de enorme importancia hoy en día en los cada vez más numerosos estudios sobre la relación entre el cerebro y la toma de decisiones. [Pues lo que se representa en el cerebro no es ni pura información, ni pura utilidad (o gusto), sino una fusión de información y valoración (no sólo de utilidad). Es como si ciertas neuronas en el córtex orbitofrontal dijeran «esto es tal cosa y la quiero (o me gusta)», es decir, determina «el valor de recompensa (reward value) del objeto reconocido», que a su vez depende de múltiples factores (de la vida personal y de la situación)].

En efecto, hay sustancias que alteran la conducta con respecto a los cánones de la teoría económica normativa. Es el caso de la oxitocina, que aumenta la conducta confiada ${ }^{33}$. Según Zak, desempeña un papel decisivo en la economía, en la medida en que "la confianza interpersonal es el factor más importante que los economistas han descubierto para explicar por qué los países son ricos o pobres»; pues la confianza favorece la prosperidad. El descubrimiento de los efectos de la oxitocina sobre el comportamiento y la interacción social se debe a Fehr y su equipo, que demostraron que niveles elevados de esa hormona en la sangre mejora la capacidad de los individuos para confiar en los demás. La oxitocina funcionaría como un lubricante natural en la vida social que contribuye a superar el temor a ser engañado. Pero lo que también han destacado algunos estudios con la administración de oxitocina es que altera la conducta de los sujetos, pero no afecta a la voluntad.

Junto a estudios sobre las bases neurológicas de la cooperación y la confianza, encontramos también investigaciones sobre la base neuronal del sentido de la justicia, aplicadas al ámbito de las decisiones económicas. Destaca en este campo el famoso experimento llamado «juego del ultimátum» ${ }^{34}$. Alan G. Sanfey hizo un estudio basándose en este juego, que consistía en poner a los jugadores de dos en $\operatorname{dos}^{35}$. Al primero se le daba una cantidad de dinero, dejando a su elección lo que quería ceder al segundo. El segundo, que conocía la cantidad

33 P. J. ZAK et al., «Oxytocin is associated with human trustworthiness», Hormones and Behavior, 48 (2005), 522-7.

34 M.A. NowaK et alii, "Fairness versus reason in the Ultimatum Game», Science, 289 (2000), 1773-1775.

35 A. G. SANFEY, "The neural basis of economic decision-making in the ultimatum game», Science, 300 (2003), 1755-8. 
total, podía aceptar la oferta o no. Si aceptaba, ganaban los dos lo que habían convenido; si rechazaba la oferta, por considerarla injusta, ambos perderían el dinero. La opción racional [según los cánones de la maximización estándar] para el segundo jugador era aceptar la oferta que le hicieran, pues algo es mejor que nada. Sin embargo, el sentido de la justicia se anteponía a la maximización racional. Los segundos jugadores preferían no obtener ningún beneficio antes que aceptar una oferta que consideraban injusta. Lo que muestra este experimento es que los seres humanos no son decisores racionales que se rijan por la maximización, sino que en las decisiones intervienen otros factores que son incluso más importantes en la resolución final ${ }^{36}$.

La aportación del enfoque neuroeconómico consiste en estudiar cómo interviene el cerebro en la toma de decisiones. Se ha detectado una activación de los hemisferios cerebrales cuando los sujetos deciden acerca de la aceptación o rechazo de ofertas injustas en la negociación. Además, desde un punto de vista neuroeconómico parece que se pueden establecer correlaciones disociando entre el juicio y la elección, porque la elección implica que el que toma la decisión tiene que asumir los costos y beneficios, mientras que el mero juicio no está asociado todavía a la asunción de los costos y beneficios ${ }^{37}$. Se amplía así el ámbito de los aspectos éticos a través de la innovación que supone la neuroeconomía.

\section{Globalización ética}

Un proyecto de economía ética ha de combinar dos niveles de reflexión: el teórico, tanto en perspectiva económica como ética, y el de los procesos globalizadores tal como se están produciendo de modo efectivo. Ahora bien, el horizonte de la globalización no se compone de la mera facticidad, sino que está grávido también de posibilidades, oportunidades y pretensiones ideales (como la de libertad y justicia). Por eso hay que orientar los procesos en un sentido humanizador, haciendo realmente posible una globalización ética.

¿Pero es posible hablar de libertad y justicia en los procesos económicos que se han puesto en marcha o son intrínsecamente malos? Hay que superar el planteamiento parmenídeo (que sólo distingue entre «ser» y «no-ser») y adoptar una actitud como la aristotélica, más acorde con la ética, que intenta detectar lo que "puede ser» (las posibilidades reales), es decir, los dinamismos que pueden orientarse para mejorar la vida humana.

Uno de los aspectos más decisivos de la globalización ha sido la financiarización de la economía. Por eso lo que hay que ver es si ésta promueve realmente los valores morales de la libertad y la justicia, o si favorece otros objetivos

36 Vid. Adela Cortina, ¿Para qué sirve realmente la ética?, Paidós, Barcelona, 2013, cap. 4.

37 Esta distinción nos recuerda la distinción aristotélica entre cognición y elección (cfr. Acerca del alma, II, 11: la facultad intelectual sola no produce movimiento), pues la cognición por sí misma no puede producir acción, ya que para influir en la conducta el sistema cognitivo tiene que operar por la vía de sistema afectivo. 
en detrimento de tales valores, que son básicos para la convivencia humana de calidad. Por ejemplo, hay que percatarse de que, si la financiarización fomenta el cortoplacismo en las inversiones de capital, tendrá efectos patológicos, porque deforma las economías, produce inestabilidad, incertidumbre, concentración de poder, creciente vulnerabilidad (especialmente de los más débiles), desigualdades injustas, pobreza y exclusión (que empieza ya por desatender al desarrollo humano).

En este contexto han sido muy significativas las propuestas de algunas tasas (como la famosa tasa Tobin), que servirían para controlar los flujos de capitales, favoreciendo la transparencia, e incluso para recaudar fondos - dada la enorme cantidad de capital que se mueve en los mercados financieros internacionales a corto plazo-, que podrían destinarse a paliar los efectos patológicos de la misma globalización y a invertir en el desarrollo humano de los menos favorecidos.

Es cierto que a muchos les está fascinando el crecimiento de los beneficios en virtud de las nuevas posibilidades en el ámbito de la producción y la comercialización (gracias a la innovación tecnológica, a los cambios en los transportes y las comunicaciones, a la libre circulación del capital), así como, sobre todo, en los nuevos mercados financieros, en los que todos los días, prácticamente sin interrupción, se mueven cifras astronómicas; pero este hecho no debe hacer olvidar que con todo ello se ha producido un clima persistente de inestabilidad y descontrol mundiales, ni tampoco que la ganancia no se ha canalizado hacia la economía real de bienes y servicios, ni hacia la creación de empleo, ni hacia el desarrollo de los más desfavorecidos y empobrecidos, sino que alimenta sobre todo la especulación financiera. De ahí que al proceso de globalización haya acompañado un aumento de las desigualdades entre los ricos (poderosos) y los pobres (áporoi), y asimismo una creciente «aporofobia» (aversión al pobre) en nuestras sociedades «avanzadas».

¿Nueva perversión del capitalismo? ¿Nos retrotrae la economía marcada por el espíritu financiero a las tendencias más perversas del capitalismo? Porque ciertamente la transformación del capitalismo ha sido muy profunda; pero podría ocurrir que estén surgiendo nuevas contradicciones a partir del desarrollo del sistema financiero y otras formas de dominación de las personas y de los pueblos, provenientes principalmente del creciente peso de la esfera financiera globalizada. Por tanto, no es ocioso preguntarse por si el capitalismo financiero puede ser un capitalismo social, inclusivo y ético, o por su propia índole es imposible domesticarlo de nuevo y reconvertirlo en un instrumento al servicio de una sociedad justa y decente, de una buena sociedad.

¿Es el sistema financiero un sistema carente de moralidad por su propia estructura y sus modos de funcionar? ¿No tiene más remedio que ampliar el número de «lacras» del que ha sido acusado el capitalismo, ya que no pone la economía al servicio del hombre sino todavía más crudamente al servicio del móvil del beneficio y del lucro ilimitado y rápido (al más corto plazo posible), sin más consideraciones? ¿Es el campo más propio para el fomento del homo oeconomicus (crematístico), bajo la consideración de que es la mejor expresión 
de la naturaleza humana (ser calculador y utilitario)? ¿Se refuerza así todavía más la «cultura» de la desigualdad, de la competición, de la lucha y la instrumentalización y mercantilización de la comunicación? Un grave peligro de la nueva situación internacional es que el capitalismo, que trató de aparecer durante décadas como un capitalismo con rostro humano, ahora crea no necesitarlo y se presente con trazos de creciente inhumanidad.

No obstante, además de quienes han insistido en que los procesos de globalización, tal como se están produciendo, fomentan el egoísmo y la avaricia (al basarse en la persecución del beneficio) y arrojan a buena parte de la sociedad a la pobreza y al desempleo (creando o manteniendo profundas desigualdades), hay también quienes han puesto de relieve entre las virtualidades de la globalización la eficacia para producir riqueza y bienestar. Y otros hasta han destacado que la economía desarrolla así un peculiar fondo moral típicamente moderno: el del interés. Éste se ha convertido en un elemento esencial de la ética social moderna, ya que constituye para muchos una garantía eficaz del orden social. En este sentido, el deseo de mejorar la propia situación constituye una fuente inagotable de beneficios para la sociedad, ya que impulsa a crear, innovar y asumir riesgos.

En el contexto actual de la nueva transformación del capitalismo, el debate entre las éticas contemporáneas en relación con la economía no puede eludir el preguntarse si en él ya no cabe la justicia social y económica, si ésta queda totalmente absorbida por el enfoque del interés y las ventajas mutuas, que lleva irremediablemente a la mercantilización de la justicia, o si es posible y razonable seguir intentando incorporar la justicia al presunto «sistema de la libertad», a fin de que ésta tenga visos de hacerse real (efectiva) en la vida de las personas.

\subsection{Críticas al desarrollo deforme del sistema financiero}

El desarrollo contemporáneo del sistema financiero parecía responder con eficacia a la exigencia de canalizar el ahorro hacia la inversión, de un modo que satisficiera cada vez más la demanda de los clientes, aprovechando todas las posibles oportunidades de beneficio.

No obstante, desde hace tiempo hubo especialistas que advirtieron del desarrollo deforme de las finanzas ${ }^{38}$, porque lo que en muchas ocasiones se ha propuesto como innovaciones financieras han sido ofertas carentes de verdadero sentido, sin auténtica garantía económica, con el solo afán de incrementar los beneficios contables. Con lo cual aumentan los riesgos, se reduce la trasparencia, se va perdiendo la confianza y se rompen los vínculos tradicionales con los clientes.

Por eso han sido muchas las voces que han expresado su preocupación y han advertido de los peligros que implicaba la fascinante «lógica» del capitalismo

38 R. CAsilda, La banca en España, Madrid, Eudema, 1993, p. 121. 
ultrafinanciero ${ }^{39}$. Preocupación por la creciente autonomización del sistema financiero, al desvincularse cada vez más en la economía mundial el movimiento de capitales del flujo de bienes y servicios. Esta tendencia podría deformar el ámbito financiero y hacerle olvidar su auténtico papel como instrumento para asignar con eficiencia recursos escasos, asumir riesgos y servir a la economía real; con lo que perdería también su legitimación económico-social y, por tanto, ética.

En una línea de reflexión semejante, también James Tobin ${ }^{40}$ consideraba que «la proliferación de operaciones financieras no sirve en muchas ocasiones para realizar más económicamente una tarea sino para inflar la cantidad y variedad de intercambios financieros, operaciones con las que huir de una regulación y obtener un beneficio privado sin la equivalencia de un beneficio social».

Por tanto, una «superestructura» financiera, «desconectada de la economía real», recortaría las posibilidades de crecimiento real de la economía mundial y separaría cada vez más el beneficio privado (rendimiento a corto plazo) del beneficio social (necesidad de inversión productiva). Porque no debería olvidarse que el sentido de la economía «simbólica» (movimientos de capital, tipos de cambio y corrientes crediticias) consiste en estar al servicio de la economía «real» (corrientes de bienes y servicios). Ésta es — creo- la razón de fondo por la que algunos propusieron un límite a la libre circulación de capitales, impulsados por el intento de dar una salida al «estado de confusión» actual mediante una nueva concepción de la economía ${ }^{41}$.

Por otra parte, también debería tenerse en cuenta la influencia que el desarrollo de este capitalismo ultrafinanciero y especulativo ha tenido y está teniendo sobre los países más pobres de la tierra. Precisamente los años de mayor desarrollo deforme del sector financiero han coincidido con el declive de las economías que fomentaban el desarrollo de los pueblos y zonas más pobres del planeta (como muestran los Informes sobre el desarrollo humano presentados por el PNUD en los últimos diez años). Por tanto, las exigencias éticas de solidaridad internacional, que reclaman los países pobres, deberían estar presentes en las reflexiones sobre el nuevo escenario global de la economía.

Así pues, las críticas al capitalismo ultrafinanciero nacen de la reflexión sobre los peligros del espíritu especulativo y de la necesaria cautela ante el «esplendor de las finanzas», ya que éste suele producir una especie de «delirio financiero especulativo, donde aparecen ganancias enormes sin fundamento real, cuyos efectos desmoralizadores realmente se subestiman» (según Maurice Allais) ${ }^{42}$.

39 GABINO IzQUIERDO, Entre el fragor y el desconcierto. Economía, ética y empresa en la era de la globalización, Madrid, Minerva ediciones, 2000; J. A. SÁnchez Asiaín, Reflexiones sobre la banca, Madrid, Espasa-Calpe, 1992, pp. 18-19, 140-143.

40 James ToBIN, "On the efficiency of the financial system», Lloyds Bank review, julio de 1984.

41 J. Borrell, «El papel del estado en la economía y en la salida de la crisis», Sistema, ${ }^{\circ}$ 117, noviembre (1993), pp. 5-18.

42 Vid. asimismo G. Soros, La crisis del capitalismo global. La sociedad abierta en peligro, Debate, Madrid, 1999. 
Y es que el capitalismo ultrafinanciero impone una determinada lógica económica, inspirada en unos determinados valores; en definitiva, se trata de la lógica del mercado puro y duro del «ultraliberalismo», donde dejándose llevar por la locura financiera sólo se busca la rentabilidad inmediata, maximizando a corto plazo el dinero convertido en "mercancía» (commodity). Este fue el sentido especulativo de los junk bonds y similares, con alto riesgo y expectativa de elevada tasa de ganancia.

Esta lógica «financiera» va contra la lógica «industrial», porque la hegemonía de la economía ultrafinanciera y especulativa puede destruir el espíritu de empresa productiva, que tiene otro ritmo y otros valores en juego. Según M. Albert, esta pugna expresa precisamente un conflicto entre dos tendencias dentro del capitalismo: 1) la que valora sobre todo el «riesgo» y el beneficio «a corto plazo», aun a costa de erosionar o destruir valores tan fundamentales como la confianza; y 2) la que valora primordialmente la «seguridad» y el beneficio «a largo plazo», porque así se pueden favorecer los vínculos sociales y fomentar valores como la confianza mediante alguna forma de organizar cierta cooperación entre los participantes en el juego financiero.

Si no se reflexiona y actúa prudentemente a tiempo, el delirio especulativo, que impulsa la lógica del capitalismo ultrafinanciero, puede acabar con la moral en la vida económica y destruir el tejido social en que se sustenta y al que debe prestar sus servicios: «el dinero entronizado amenaza con barrer toda moral» ${ }^{43}$.

\subsection{Repercusiones sociales}

La forma tal vez más extendida de razonar en contra de la globalización ha sido aquélla que resalta las repercusiones sociales de los cambios producidos en la economía globalizada.

Una de las repercusiones sociales a la que todos los estudiosos de la globalización aluden es la desestructuración de las instituciones modernas, entre las que sobresale el estado. Se suele destacar el hecho de que el estado nacional moderno es incapaz de hacer frente a las fuerzas globalizadoras. El estado-nación está en crisis, o bien debido a su debilitamiento, o bien a la desorientación ante la innegable necesidad de reestructurar sus funciones socio-económicas.

Otro de los efectos inaceptables de la globalización está siendo el acrecentamiento del abismo que separa a los ricos y poderosos de los pobres (los áporoi). Es una auténtica contradicción proclamar que toda persona es libre e igual y mantener en la práctica unas desigualdades tan injustas. Al proceso de globalización ha acompañado un aumento de las desigualdades entre los países y entre las personas. Y no se puede alegar desconocimiento de esas desigualdades, ni falta de medios para empezar a remover las situaciones. Lo único que falta es voluntad real y decisión.

\footnotetext{
43 M. Albert, Capitalismo contra capitalismo, Barcelona, Paidós, 1992, p. 80.
} 
Abruma pensar que la mayoría de la población mundial está al excluida no sólo del disfrute de los bienes y servicios de que dispone la humanidad, sino aún más de los procesos en los que se toman las decisiones mundialmente relevantes y que afectan a su vida. Los pobres ya no cuentan para nada, carecen de todo tipo de poder, porque no pueden ni siquiera negociar para hacer valer sus exigencias. Están al margen de cualquier participación significativa sobre su futuro. Se acrecienta y agudiza la práctica de la aporofobia, que casi todo el mundo intenta recubrir mediante otras terminologías, rehuyendo llamar a la realidad por su nombre: aversión por el pobre, el desvalido, el que no tiene nada que ofrecer a cambio, en el terreno que sea (económico, político, jurídico, de opinión pública).

La «globalización» a secas no arregla nada. El tan repetido cuento de la «aldea global» suena a nana para los que quieren dormirse apaciguados con su propio éxito, ya que globalizar sin las condiciones para, a la vez, integrar, implica aumentar las dimensiones de la jungla global. Sin las exigencias de justicia y solidaridad de una ética cívica universal constituye una irresponsabilidad asistir sin más a una globalización unilateral, cuando la inmensa mayoría de la humanidad queda fuera del desarrollo auténticamente humanizador.

\subsection{Nuevas perspectivas e iniciativas}

(1) Conciencia de la necesidad de una ética universal

Desde hace ya tiempo se han hecho oír algunas voces que reclaman una perspectiva ética para orientar debidamente los procesos de la globalización y hacer frente a los nuevos problemas de orden planetario. Se trata de una ética universal, capaz de proporcionar un marco axiológico y normativo a la política y economía internacionales, a las inmensas potencialidades de las nuevas tecnologías de la información y de la comunicación. De ahí que se haya resaltado cada vez más la «necesidad de una ética universal como una macroética planetaria de corresponsabilidad en la era de la ciencia y de la tecnología ${ }^{44}$.

Una ética de la responsabilidad o, mejor, de la corresponsabilidad, orientada por la justicia, el cuidado y la solidaridad: no sólo personal, sino social e institucional; no sólo del desinterés, sino capaz de cribar y orientar los complicado mundo de los intereses; no sólo basada en convicciones y principios, sino atenta a las consecuencias, a los peligros y los riesgos de las acciones y decisiones en el ejercicio del creciente poder interventor en la naturaleza y en la sociedad.

(2) Superar la financiarización de la economía global, para propiciar un nuevo estilo de vida más humano y humanizador, centrado en las auténticas necesidades de las personas y en los verdaderos problemas de la humanidad.

44 K. O. APEL, «El apriori de la comunidad de comunicación y los fundamentos de la ética», en La transformación de la filosofía, Madrid, Taurus, 1985, vol. II, pp. 341-413; «Globalización y necesidad de una ética universal», en A. Cortina y D. GARCíA-MARZÁ (eds.), Razón pública y éticas aplicadas, Madrid, Tecnos, 2003, pp. 91-218; A. CoRTINA, Razón comunicativa y responsabilidad solidaria, Salamanca, Sígueme, 1985; Ética mínima, Madrid, Tecnos, 1986; H. Jonas, El principio de responsabilidad, Barcelona, Herder, 1995. 
El crecimiento exponencial de los mercados financieros ha tenido consecuencias positivas como la alta disponibilidad de crédito para financiar el consumo y la inversión, el crecimiento y el empleo. Sin embargo, la imprudencia y la ineficiente supervisión propiciaron asumir riesgos fatales, que han producido inestabilidad. La desmesura financiera requiere corrección y un control racional de las actividades ${ }^{45}$. Porque, como el propio Samuelson afirmó, «los sistemas de mercado no regulados acaban destruyéndose a sí mismos» y son «la fuente primaria de nuestros problemas de hoy ${ }^{46}$, porque el capitalismo financiero se ha desbocado. Hace falta recapacitar y atenerse a la indicación de Roosevelt: «Prefiero rescatar a los que producen alimentos que a los que producen miseria». Y en los últimos tiempos, incluso quienes contribuyeron a la financiarización actual, como el ex director general de Citibank, Sandy Weill, han reconocido que "permitir la fusión de los cancos comerciales con los de inversión fue un error». Por tanto, hay que reconstruir y fortalecer la economía real, y «el que quiera arriesgar que lo haga en Wall Street» y con su propio dinero, no con el del conjunto de los depósitos de todos los ciudadanos (incluso de los que no quieran participar de ese juego tan peligroso).

Las tasas para las transacciones financieras, como la tasa $\operatorname{Tobin}^{47}$, pueden contribuir a desincentivar las transacciones que favorecen el flujo de capitales especulativos en operaciones a muy corto plazo y disuadir a los especuladores, por tanto, pueden servir al objetivo de limitar el excesivo poder de los mercados financieros. El propio Tobin aclaró que estaba influido por Keynes, quien en el capítulo XII de su Teoría general del empleo, del interés y del dinero ya había ideado una tasa para las transacciones financieras, porque la excesiva especulación aumentaba la volatilidad de los mercados. Es necesario regular mejor los mercados financieros, para que sea posible atender a la exigencia básica de justicia, empezando por la satisfacción de las necesidades.

(3) La gestión de la globalización (¿Gobernanza?)

Los procesos son fruto de decisiones y de acuerdos internacionales. Por tanto, habría que atender a las consecuencias. Son fruto de decisiones institucionales, de las que hay responsables. Hay que reflexionar sobre el modo de vida que propician estos procesos de transformación de la economía mundial. Si favorece la libertad real para todos o no. Si favorece la justicia o si genera más desigualdades injustas. Si contribuye a crear un clima solidario o si propicia la guerra económica (y no solo económica) y la jungla global.

Reputados estudiosos, como Castells, reconocen la estrecha vinculación entre la economía y la política en la fase actual de desarrollo. Hay una integración compleja entre Política y Economía, dado que la economía global e

45 Kenneth Galbraith, Breve historia de la euforia financiera, 1991.

46 Paul Samuelson, «Adiós al capitalismo de Friedman y Hayek», El País (26-10-2008).

47 J. Toвin, Janeway Lectures, Universidad de Princeton, 1971; vid. entrevista en Der Spiegel 3 de septiembre de 2001). 
internacional es «una economía altamente politizada» ${ }^{48}$. El aumento de la competencia de mercado a escala global tiene lugar «en condiciones de comercio gestionado ${ }^{49}$. De tal manera que la innovación empresarial está combinada con estrategias de gobierno. La nueva economía, basada en la reestructuración socioeconómica y la revolución tecnológica, será configurada según procesos políticos conducidos por el Estado.

Surge así un nuevo papel económico delos Estados en la era e la desregulación. Cuando algunos sólo hablan del debilitamiento del Estado o de su desaparición, hay que reflexionar más a fondo sobre su nuevo papel y sus nuevas funciones, su modo de transformarse en una institución eficiente y adecuada al actual desarrollo de la sociedad mundial. Porque lo crucial de la nueva sociedad informacional, según Castells, es la integración compleja entre las instituciones políticas y los agentes económicos (cada vez más globalizados). De ahí la necesidad de una sinergia institucional en un medio y unos tiempos acostumbrados al conflicto, pero sin confundirla con las connivencias entre el poder económico, el político y el mediático, pues en el desarrollo financiero e informacional de la economía todos los poderes están estrechamente ligados.

(4) Hay que afrontar la tendencia a la desigualdad económica, que tiene graves repercusiones para la vida política democrática. El libro de Piketty, El capital en el siglo XXI ha vuelto a poner de relieve que la causa de la desigualdad es la forma en que se ha desarrollado el capitalismo. La causa consiste en que la tasa de beneficio del capital es sistemáticamente mayor que la tasa de crecimiento de la economía, que es lo que beneficia a la mayoría de la gente. Tenga razón o no en su diagnóstico etiológico, la aportación de Piketty consiste, al menos, en haber puesto de relieve la necesidad de atender a este aspecto de la justicia distributiva, para cuya resolución hace falta una nueva forma de gestionar las actividades económicas dentro de un horizonte ético de justicia global, corrigiendo sus tendencias perversas, como la desmedida financiarización, rediseñando las instituciones del «Estado Social de Justicia» (que no se confunde con el de «bienestar») ${ }^{50}$.

(5) En la misma línea de rectificar los abusos en el ámbito de las finanzas se ha manifestado la directora gerente del Fondo Monetario Internacional, Lagarde, que ha acusado a los bancos de frenar e intentar parar las reformas internacionales ${ }^{51}$. En su intervención en la «Conference on Inclusive Capitalism» denunció la lentitud con la que se está aplicando la reforma del sistema financiero global. Se ha perdido la confianza en el sistema financiero, porque está produciendo un aumento de la desigualdad ${ }^{52}$. Tendría que haber

48 M. CASTELLS, La era de la información, vol. I, p. 117.

49 Ibid.

50 Adela Cortina, Ciudadanos del mundo, Alianza, Madrid, 1997, cap. III.

51 El País, 28 de mayo de 2014.

52 Las 85 personas más ricas del mundo cabrían en un autobús de Londres, controlan tanta riqueza como la mitad más pobre de la humanidad. 
«más inclusión en el crecimiento económico y más honradez en el sistema financiero». Estos términos (la inclusión social y la honradez) implican un horizonte ético de la economía. Y una de las propuestas prioritarias que ha defendido Lagarde es acabar con el «too big to fail», porque va contra el sentido de la justicia.

(6) «Semillas» de economía justa: nuevas iniciativas de economía ética. Están surgiendo iniciativas desde diversos sectores de la sociedad civil ${ }^{53}$, aunque no siempre suficientemente atendidas por la corriente principal del análisis socioeconómico académico. Son propuestas de modelos de empresa, de consumo y de inversión, en las que la actividad económica desempeña una función instrumental para resolver problemas concretos de la sociedad, para satisfacer necesidades sociales básicas, porque aspiran a una sociedad más justa. No priorizan la rentabilidad, sino que pretenden lograr una economía al servicio de las personas. Tratan de recuperar el sentido social de la actividad financiera y del propio dinero, apoyando proyectos de especial relevancia social (en favor de desfavorecidos o excluidos del sector financiero convencional), o creando entidades financieras éticas (banca ética). Se pretende mostrar que es posible poner en marcha en la práctica alternativas de economía justa, de otra forma de vida y de sociedad ${ }^{54}$. Son propuestas que alimentan la esperanza.

(7) Algunas de ellas se están institucionalizando, como las que promueven la «Responsabilidad Civil de la Empresa ${ }^{55}$, más allá de la Responsabilidad Social Empresarial o Corporativa, ya que hay quienes consideran que «el papel de las empresas en la sociedad es la cuestión más importante de la política pública del siglo XXI. La empresa va forjando cada vez más los valores y las normas sociales.... ${ }^{56}$. El marco de esta propuesta es el de una «economía civil» como innovación social (cuyas raíces se encuentran en el humanismo cívico del siglo XV y su desarrollo en la Ilustración italiana del XVIII) ${ }^{57}$.

(8) Otro de los intentos de institucionalización internacional es el logrado en 2011, cuando el Consejo de Derechos Humanos de las Naciones Unidas apoyó los «Principios Rectores sobre las empresas y los derechos humanos», elaborados

53 Vid. José Ángel Moreno, «Semillas de economía alternativa», en el número 26 (2014) de la revista Mediterráneo Económico, no 26 (2014), monográfico sobre «La responsabilidad ética de la sociedad civil», pp. 291-307. Con ejemplos de social lending y crowdfunding, etc.

54 M. Kinsley, Creative capitalism, New York, Simon \& Schuster, 2009; Robert Shiller, Finanzas y sociedad justa, 2012.

55 Stefano ZamagnI, «El reto de la responsabilidad civil de la empresa», en Mediterráneo Económico, no 26 (2014), pp. 209-225; M.E. PORTER y M.R. KRAMER, «Creating shared value. How to reinvent capitalism and unleash a wave of innovation and growth», Harvard Business Review, 89, 1-2, pp. 81-96.

56 SimON ZADEK, The Civil Corporation. The new economy of corporate citizenship, Earthscan, Londoon, 2001, pp. 1-2.

57 Aquí, la economía no se identifica con el mercado, que se sostiene en valores de fuera del mercado, y la política no se identifica con el Estado, que asimismo se sostiene en valores de fuera del Estado. 
por el Representante Especial del Secretario General de acciones Unidas para dicha cuestión, John Ruggie. Sus directrices principales son la de "proteger, respetar y remediar»: proteger de los abusos, respetar los derechos humanos $\mathrm{y}$ «remediar» (reparar) a las víctimas ${ }^{58}$. Este marco es un gran paso, pero es insuficiente, de ahí que se esté abogando por una convención internacional con carácter vinculante, para hacer efectivos los Principios Rectores, mediante alguna regulación de las actividades de las empresas transnacionales en favor de los derechos humanos.

Si fuera cierto, como algunos creen, que existe una convergencia económica como base impulsora de la convergencia cultural a través de los procesos de globalización, que está produciendo a la vez una homogeneización económica y cultural, es ineludible plantearse si lo que se está imponiendo es la mercantilización de la vida entera, erosionando el pluralismo y provocando un empobrecimiento de las formas de existencia, o si optamos por promover una auténtica globalización ética, basada en la justicia global y los derechos humanos.

Universidad de Valencia

Jesús Conill Sancho

Jesus.Conill@uv.es

[Artículo aprobado para publicación en diciembre de 2015]

58 John Ruggie, Constructing the World Polity: Essays on International Institutionalization, New International Relations, Routledge, 1998; Just Business: Multinational Corporations and Human Rights, Norton, New York, 2013. 